\title{
Micro, pequeñas \\ y medianas empresas en América Latina
}

\section{Emilio Zevallos V.}

Consultor Senior del Programa

Mejora de las Condiciones del

Entorno Empresarial,

Fundación para el

Desarrollo Sostenible

(FUNDES)

ezevallos@fundes.org
Este artículo presenta las características y situación de las microempresas, pequeñas empresas y medianas empresas (mipyme) en varios países de América Latina. Inicialmente, recoge las definiciones más habituales en estos países y establece una cuantificación de tales definiciones en cada uno de ellos, así como su distribución sectorial y regional. Luego analiza las condiciones del entorno que influyen en la conducta de las empresas, sus problemas y la respuesta pública; en estos ámbitos, examina el grado de desarrollo institucional de la región y su impacto en el comportamiento empresarial. Finalmente, y considerando elementos de la oferta y de la demanda, plantea oportunidades de mejora y mecanismos de articulación público-privada. Asimismo, establece algunas áreas de problemas empresariales y formula propuestas para una mayor y mejor participación de los responsables del diseño y ejecución de las políticas de fomento en la región. 


\section{Introducción}

Las condiciones que generaron el interés por las microempresas y las pequeñas y medianas empresas (mipyme) en América Latina hace más de una década no sólo no han cambiado significativamente, sino que en muchos casos se han agudizado por la presencia de nuevos elementos que han de considerarse en el escenario económico internacional (el desarrollo de nuevas tecnologías, el proceso de internacionalización y otros). Además, las recurrentes crisis económicas en varios países de la región han afectado de diversa manera el desempeño de estos estratos empresariales. Lo anterior ha servido tanto para resaltar la importancia de las mipyme como generadoras de empleo (aunque precario) y promotoras de avances en el entorno local, como por su potencialidad de convertirse en un importante complemento del trabajo de la gran empresa.

Pero más allá de estas consideraciones, la vocación local de las mipyme desde su origen y las exitosas experiencias de los sistemas de producción basados en ellas - tanto en su relación con grandes empresas como en sus relaciones recíprocas a nivel localmuestran lo que se puede lograr con ellas en términos de crecimiento económico y redistribución del ingreso. Las experiencias que han tenido lugar en Italia (Emilia Romana), Alemania (Baden-Wüttemberg) y Estados Unidos (Sillicon Valley) exhiben como común denominador la presencia de densas redes de mipyme capaces de generar productos competitivos de manera colectiva.

Por otro lado, si consideramos que sólo alrededor del $20 \%$ del producto bruto mundial se comercializa internacionalmente (Alburquerque, 1997), podemos tener una clara visión de la importancia de la actividad local de las microempresas y las pequeñas y medianas empresas en el desarrollo de los países latinoamericanos.

En este sentido, una de las tareas primordiales de las instituciones públicas y privadas de la región es la de aprovechar ese potencial de las mipyme en el ámbito local, considerando que aproximadamente el $80 \%$ de las decisiones económicas de los países tienen una perspectiva interna.

El presente artículo busca presentar una visión panorámica de la situación de las mipyme en varios países de América Latina (en los que opera la red FunDES $)^{1}$ y a la vez — a nivel agregado- proponer algunas áreas en las que las organizaciones públicas, privadas e intermedias de la región debieran participar de manera más activa. Para ello se busca identificar algunos "espacios vacíos" entre demanda y oferta orientada a las mipyme o en nichos inadecuadamente atendidos para este grupo de empresas, que está considerado muy dinámico y poseedor del mayor potencial de desarrollo productivo (en relación a su tamaño).

\section{II}

\section{Las mipyme: cómo se definen, cuántas son y dónde están}

Ante la necesidad de información sobre las empresas de menor tamaño, la primera pregunta que surge es:

\footnotetext{
$\square$ Este trabajo es parte de un proyecto de la FUNDES sobre indicadores de las pequeñas y medianas empresas (pyme) para América Latina. Agradezco los comentarios de Albert Berry y de un juez externo de la CEPAL, así como la amplia colaboración para el desarrollo de este trabajo prestada por todas las unidades de mejora de las condiciones del entorno empresarial de la FUNDEs que funcionan en 10 países (en adelante a estas unidades las llamaremos unidades de entorno).
}

¿para qué definir los estratos empresariales? Las respuestas posibles son al menos dos: i) para fines puramente estadísticos, y ii) para fines vinculados a consi-

\footnotetext{
${ }^{1}$ La red FUNDES comprende 10 países donde esta fundación provee servicios de consultoría, formación, mejora de las condiciones del entorno empresarial, e-business y otros. Estos países son Argentina, Bolivia, Chile, Colombia, Costa Rica, El Salvador, Guatemala, México, Panamá y Venezuela.
} 
deraciones de política. Pero más allá de sus fines, la definición siempre ayudará a conocer la magnitud de cada segmento de empresas (y por ende su impacto en la actividad productiva), y a tomar medidas mejor enfocadas de fomento de la producción.

Los resultados obtenidos tanto de nuestra investigación documental como de la indagación en la red FUNDES nos permiten una primera aproximación al grado de heterogeneidad de la situación de las mipyme en América Latina. Así, podemos afirmar que en los países de la región se aplican diversos criterios para definir a las empresas: empleo, ventas, activos y otros (cuadro 1). En varios países existe más de un criterio (y, por tanto, más de una definición). Sin embargo, las definiciones se basan con más frecuencia en el empleo (ocho países), las ventas/ingresos (seis países) y los activos (cuatro países). Además, algunos países hacen diferencias en la definición, dependiendo de si la unidad económica es manufacturera, comercial o de servicios. Inclusive, hay países en los que las definiciones varían según la institución que las establece y, por lo tanto, cada institución aplica la propia para formular sus políticas de fomento.
Sobre la base de las definiciones mencionadas en el párrafo anterior, se determinó el número de empresas en cada uno de los países considerados (cuadro 2), utilizando fuentes oficiales - como censos económicos, cuando se dispuso de ellos_-, o cuantificaciones públicas o privadas consideradas significativas. La mayor parte de la información corresponde a la segunda mitad del decenio de 1990 (salvo para Colombia y Argentina). En algunos casos los datos disponibles corresponden sólo al sector de manufacturas y en otros se consideran muestras que de alguna forma son representativas; algunos países sólo entregan información de empresas con algún tipo de registro. De lo dicho se puede inferir que la muestra subestima el número real de unidades económicas de cada país y, por ende, de América Latina. Sin embargo, constituye un primer punto de referencia de la realidad de las empresas en la región.

Aunque no tiene demasiado sentido sumar las cifras del cuadro (por los problemas señalados en el párrafo anterior), si de todas formas hacemos el ejercicio, encontraríamos que hay aproximadamente 6.2 millones de unidades económicas de diverso tamaño en los países considerados.

Definiciones de las empresas

\begin{tabular}{|c|c|c|c|c|c|}
\hline & Criterios & Microempresa & Pequeña empresa & Mediana empresa & Gran empresa \\
\hline Argentina $^{\mathrm{a}}$ & Ventas & Hasta 0.5 & Hasta 3 & Hasta 24 & Más de 24 \\
\hline Bolivia $^{b}$ & Empleo & Hasta 10 & Hasta 19 & Hasta 49 & Más de 49 \\
\hline Chile $^{\mathrm{c}}$ & Ventas & Hasta 2400 & Hasta 25000 & Hasta 100000 & Más de 100000 \\
\hline Colombia $^{\mathrm{d}}$ & Empleo & Hasta 10 & Hasta 50 & Hasta 200 & Más de 200 \\
\hline Costa Rica ${ }^{\mathrm{e}}$ & Empleo & Hasta 10 & Hasta 30 & Hasta 100 & Más de 100 \\
\hline El Salvador ${ }^{f}$ & Empleo & Hasta 4 & Hasta 49 & Hasta 99 & Más de 99 \\
\hline Guatemalag $^{g}$ & Empleo & Hasta 10 & Hasta 25 & Hasta 60 & Más de 60 \\
\hline México ${ }^{h}$ & Empleo & Hasta 30 & Hasta 100 & Hasta 500 & Más de 500 \\
\hline Panamái & Ingresos & Hasta 150000 & Hasta un millón & Hasta 2.5 millones & Más de 2.5 millones \\
\hline Venezuelaj & Empleo & Hasta 10 & Hasta 50 & Hasta 100 & Más de 100 \\
\hline
\end{tabular}

Fuente: Elaboración de las unidades de entorno de la red FUNDES con datos emanados de la Secretaría de la Pequeña y Mediana Empresa y Desarrollo Regional (sepyme) de Argentina; el Viceministerio de Microempresa, Ministerio de Trabajo (Bolivia); la Encuesta de Caracterización Socioeconómica Nacional (CASEN) y la Corporación de Fomento de la Producción (CORFO), de Chile; la Ley mipyme de julio de 2000 (Colombia); el Ministerio de Economía (Costa Rica); la Dirección General de Estadística y Censos (El Salvador); el Instituto Nacional de Estadística, la Cámara de Comercio y Promicro (Guatemala); el Consejo Nacional para la Micro, Pequeña y Mediana Empresa (México), la Ley 33 y la Ley 8 del año 2000 (Panamá), y la Oficina Nacional de Estadística e Información (Venezuela).

a En millones de pesos. Definición para manufactura. Además hay otras para el comercio y los servicios, también por ventas anuales.

b Existen varios criterios: por empleo, por ventas y por activos. Sin embargo, la definición oficial se basa en el empleo.

c En unidades de fomento (UF). Una UF equivale aproximadamente a 24 dólares. También existe otra definición, por empleo.

d Existen dos definiciones: por empleo y por activos.

e Existen otras definiciones por inversión y por ventas anuales.

f Las definiciones oficiales son por empleo y por activos (Comisión Nacional de la Micro y Pequeña Empresa-CONAMYPE).

g Definición del Instituto Nacional de Estadística. Hay otras dos más, la de la Cámara de Comercio y la de Promicro (todas ellas se basan en el empleo).

h Definición para la manufactura. Además hay otras para el comercio y los servicios, también basadas en el empleo.

i En balboas o dólares (paridad uno a uno).

j Definición únicamente para la manufactura. No hay definiciones para el comercio o los servicios. 
América Latina (10 países): Número de empresas

\begin{tabular}{|c|c|c|c|c|c|c|}
\hline País & Año de la información & Microempresa & Pequeña empresa & Mediana empresa & Gran empresa & Total \\
\hline Argentina $^{\mathrm{a}}$ & 1994 & 814400 & 69500 & 7400 & 5200 & 896500 \\
\hline Bolivia $^{\mathrm{b}}$ & 1995 & 500000 & 1007 & 326 & 234 & 501567 \\
\hline Chile $^{\mathrm{c}}$ & 1997 & 432431 & 78805 & 10870 & 4814 & 526920 \\
\hline Colombia $^{\mathrm{d}}$ & 1990 & 657952 & \multicolumn{2}{|c|}{26694} & 821 & 685467 \\
\hline Costa Rica ${ }^{\mathrm{e}}$ & 2000 & 58620 & \multicolumn{2}{|c|}{14898} & 1348 & 74866 \\
\hline El Salvador ${ }^{\mathrm{f}}$ & 1998 & 464000 & 12398 & 502 & 316 & 477216 \\
\hline Guatemalag & 1999 & 135000 & 29024 & 9675 & 2438 & 176137 \\
\hline Méxicoh & 1998 & 2676327 & 85223 & 24461 & 7307 & 2793318 \\
\hline Panamái & 1998 & 34235 & 5601 & 1149 & 1239 & 42224 \\
\hline Venezuela $^{\mathrm{j}}$ & 2000 & $\ldots$ & 8701 & 2613 & 776 & $\ldots$ \\
\hline
\end{tabular}

Fuente: Elaboración de las unidades de entorno de la red FUNDES, con datos de las fuentes citadas en el cuadro 1.

a Son 903 995, incluyendo las denominadas empresas auxiliares. Datos del censo nacional económico que efectúa el Instituto Nacional de Estadística y Censos (INDEC, 1994).

b Estimación del Centro de Estudios para el Desarrollo Laboral y Agrario (CEDLA).

c Datos de la CORFO.

d Datos del censo económico que efectúa el Departamento Administrativo Nacional de Estadística (DANE, 1991). Sin embargo, otras fuentes señalan que para 1991 había casi un millón de empresas (Econometría Ltda.).

e No hay desglose entre pequeña y mediana empresa. Datos de Castillo y Chávez (2001).

f Sólo industria, comercio y servicios. Datos del Ministerio de Economía, y de la Comisión Nacional de la Micro y Pequeña Empresa obtenidos de la encuesta económica anual (CONAMYPE, 2002) y de la encuesta microempresarial (CONAMYPE, 1995).

g Empresas industriales únicamente en la región metropolitana. Datos del Instituto Nacional de Estadística, Censo Industrial.

h Sólo en la manufactura, el comercio y los servicios; incluyendo otras unidades económicas, existen 3.1 millones. Datos del Instituto Nacional de Estadística, Geografía e Informática (INEGI), censos económicos.

i Datos del Directorio de Establecimientos que prepara la Secretaría de la Contraloría y Desarrollo Administrativo.

j Sólo empresas industriales. Datos del Instituto Nacional de Estadística (antes OCEI). No hay información oficial de microempresas ni de empresas comerciales y de servicios. Hay una estimación del programa Bolívar de alrededor de 480 mil empresas (Páez, 2001 ).

En rigor, y utilizando las definiciones oficiales en cada país, las pequeñas y medianas empresas en nueve países serían al menos 400000 (con las peculiaridades y sesgos de la información ya mencionados), excluyendo las llamadas microempresas de acumulación, que forman parte de la "empresa media".

El término "empresa media" fue acuñado en México para refundir en un solo grupo a las pyme y a aquellas microempresas que denominamos "con opción de desarrollo". Esta nueva clasificación profundiza la forma común de dividir las microempresas entre las de subsistencia y aquéllas con opción de desarrollo, utilizando como único criterio el número de trabajadores que laboran en ellas. Si bien la variable número de trabajadores da una idea cuantitativa de la microempresa, no entrega ningún indicio sobre sus características cualitativas. Es preciso entonces incluir factores que reflejen la actitud empresarial.

Para incluir estos factores se ocuparon algunas preguntas de la Encuesta Nacional de Micronegocios de México 1996, confeccionada por el INEGI. En particular, se trabajó con cuatro preguntas. Las dos primeras se refieren a cuestiones estructurales: el tipo de estructura jerárquica prevaleciente en la empresa y aspectos físicos de ésta. Las otras dos tienen que ver con las aptitudes o características emprendedoras del empresario: el motivo para iniciar su actividad y sus perspectivas respecto a la empresa. ${ }^{2}$

\footnotetext{
${ }^{2}$ La primera pregunta se refería al tipo de empresario; las opciones eran empleador $(16.2 \%)$ o trabajador por cuenta propia (83.8\%). La segunda consultaba sobre la posibilidad de tener local propio (71\%) y de no poseer local $(21 \%)$. La tercera inquiría el motivo del dueño para iniciar su actividad y las posibles respuestas eran: tradición familiar $(6.2 \%)$; para complementar el ingreso familiar $(28.7 \%)$; por obtener un ingreso mayor que como asalariado (32.9\%); no haber encontrado empleo como asalariado $(19.2 \%)$; horario flexible $(4.5 \%)$; despido por recorte de personal $(3.2 \%)$ y otro $(5.3 \%)$. Se consideraron como indicativas de empresarios emprendedores las opciones 1 y 3 , con lo que éstos comprenderían 39.1\% de los microempresarios y el $60.9 \%$ de los de subsistencia. Por último, se consideraron las expectativas de los empresarios respecto de su actividad y los resultados fueron:

1) Continuar con su negocio:

1.1 Sin cambios importantes $\quad 67.7 \%$

1.2 Ampliando la línea de productos $\quad 7.2 \%$

1.3 Realizando nuevas inversiones $\quad 9.5 \%$

1.4 Aumentando el número de trabajadores $\quad 0.8 \%$

1.5 Con otro plan $2.2 \%$

$\begin{array}{ll}1.6 \text { No sabe } & 0.8 \%\end{array}$

2) Cambiar de actividad

3) Abandonar y emplearse como asalariado $\quad 3.3 \%$

4) Abandonar con otro plan $1.3 \%$

5) No sabe $1.3 \%$
}

Se consideraron como indicativas de una perspectiva emprendedora las respuestas $1.2,1.3,1.4$ y 1.5 . Así el $19.7 \%$ tiene una actitud emprendedora, mientras que el $80.3 \%$ no, al menos explícitamente (Zevallos, 2000). 
Con base en las estadísticas resultantes de cada respuesta se hizo un promedio simple de cinco variables (las cuatro preguntas más el número de trabajadores), del que se desprende el alcance cuantitativo de la empresa media para el caso de México. De esta manera, la empresa media estaría conformada por las empresas medianas y pequeñas y por el $25.3 \%$ de las microempresas. Este último resultado es semejante al que señalan estudios como el de la Organización de Cooperación y Desarrollo Económicos (OCDE, 1997), donde se plantea que una proporción significativa de las microempresas, quizás un $25 \%$ o más, está orientada al crecimiento y desempeña un importante papel en la generación de dinamismo y flexibilidad en la economía.

Quizá sobre esta base se pueda especular que también alrededor del $25 \%$ de las microempresas pueda ser catalogada como empresa media. Si se agregan las empresas pequeñas y medianas, estaríamos hablando de un poco más de 1.6 millones de empresas en estos países de la región que pueden ser el objetivo de las acciones encaminadas a fomentar la mejora competitiva. ${ }^{3}$

Cabe destacar que para este grupo de países alrededor del $92 \%$ de todas las unidades productivas cubiertas por las estadísticas del cuadro 2 son definidas como microempresas, algo más del $7 \%$ son pyme, y algo menos del $1 \%$ son definidas como grandes empresas.

Esta información contrasta con la idea generalizada del peso de las pyme en la estructura empresarial, o al menos con la frecuente confusión entre pyme y MIPYME. En ese sentido, la adopción de un concepto como el de "empresa media" sería un avance en la planeación de una política de fomento productivo concertada entre el sector público y el sector privado de la región.

Es necesario reconocer las diferentes características de los diversos estratos que comprende la "empresa media" - mediana, pequeña y un sector de la microempresa- y, por ende, los diferentes tipos de medidas de fomento que cada uno de ellos necesita. El grado de desarrollo relativo de cada estrato empresarial determina en muchos casos sus necesidades de apoyo y/o fomento. En el caso de la microempresa, las

\footnotetext{
${ }^{3}$ Considerando tres grupos de empresas - microempresas con opción de desarrollo, empresa media y gran empresa-, cada uno de ellos con características y necesidades diferentes. Aunque debe tenerse presente que la inferencia hecha para la región es arriesgada, porque a pesar de que la proporción de microempresas que forman parte de las empresas medias en México (25.3\%) es muy parecida a la que exhibe la oCDE $(25 \%)$, esto no significa necesariamente que toda la región posea la misma estructura productiva.
}

políticas generadas a lo largo del tiempo han tenido un claro sesgo asistencialista que sólo ha reproducido la situación de este estrato y no ha logrado mejorarla cualitativamente. Sacar de este estrato a su grupo más dinámico e incorporarlo al de la "empresa media" sería un aporte, pues así dicho grupo podría acceder a medidas más enfocadas a su propia realidad.

De otro lado, la distribución geográfica y sectorial de las empresas nos indica dónde se encuentran las concentraciones empresariales y cuál es su actividad económica preponderante. Sus patrones de localización territorial están asociados —en principio — a su dotación de recursos o a sus ventajas comparativas. Por ejemplo, las exportadoras buscan lugares con buena dotación de infraestructura física (transportes y comunicaciones) y a las que desarrollan productos les interesa la proximidad de instituciones educativas.

Investigaciones de la red FUNDES revelan una alta concentración empresarial en las capitales de los países, así como en las ciudades más importantes. Esto se debería a que la concentración de las actividades en grandes ciudades genera economías de aglomeración que permiten reducir los costos de producción en muchas actividades económicas. Además, en las aglomeraciones se puede mejorar la relación costo-eficacia - es decir, la eficiencia-, merced a la concentración poblacional, la gran cantidad de distribuidores, la presencia de servicios financieros y comerciales y el acceso a información de mercados externos y a tecnología, entre otros factores. En ese escenario, las empresas de baja productividad (como las pyme) se benefician también de los encadenamientos productivos que se generan. Esto contribuye a la concentración de las pyme también en las grandes ciudades.

La evidencia sobre los procesos de desarrollo regional en América Latina muestra que las concentraciones poblacionales son resultado de las concentraciones de actividad económica, consecuencia a su vez de la identificación de alguna ventaja comparativa o de economías de aglomeración. El cuadro 3 muestra la fuerte concentración empresarial existente en algunos de los países en desarrollo considerados, lo que más que casos particulares refleja la situación general en la región.

Como se puede apreciar, en todos los casos la mayor concentración empresarial se da en la capital y en las regiones económicamente más importantes de los países.

También es posible aproximarse a información sectorial relevante (sobre la base de las proporciones en que se combinan la manufactura, el comercio y los 
CUADRO 3

América Latina (ocho países): Número de regiones (estados/departamentos) que concentran el $\mathbf{5 0 \%}$ de las empresas

\begin{tabular}{lcc}
\hline & Porcentaje & $\begin{array}{c}\text { Número de regiones } \\
\text { respecto del total }\end{array}$ \\
\hline Argentina $^{\mathrm{a}}$ & 55.2 & $3 \mathrm{de} 20$ \\
Chile $^{\mathrm{b}}$ & 48.5 & $2 \mathrm{de} 13$ \\
Colombia $^{\mathrm{c}}$ & 49.0 & $1 \mathrm{de} 7$ \\
Costa Rica $^{\mathrm{d}}$ & 74.8 & $1 \mathrm{de} 6$ \\
El Salvador $^{\mathrm{e}}$ & 55.3 & $2 \mathrm{de} 14$ \\
Méxicof $^{\mathrm{f}}$ & 48.1 & $6 \mathrm{de} 32$ \\
Panamág $^{\text {Venezuela }}$ & 52.4 & $1 \mathrm{de} 9$ \\
hen $^{\mathrm{h}}$ & 51.5 & $2 \mathrm{de} 9$ \\
\hline
\end{tabular}

Fuente: Elaboración de la FUNDES, con información recopilada por las unidades de entorno de la red FUNDES.

a Capital Federal + Gran Buenos Aires + resto de Buenos Aires.

b Región Metropolitana y Bío Bío.

c Sólo Bogotá (le siguen Valle con 15\% y Antioquia con 14\%).

d Región central .

e San Salvador y Santa Ana (luego La Libertad con $11.4 \%$ y San Miguel con $10.6 \%$ ).

f México, D.F., estado de México, Veracruz, Jalisco, Puebla y Guanajuato.

g Sólo Panamá (le sigue Chiriquí con 14.8\%).

h Zona de la capital y central (sigue la centro-occidental con 16.7\%).

servicios). Como se ve en el cuadro 4 , los datos revelan asimismo una alta concentración de la actividad comercial y de servicios en la mayor parte de los países para los que contamos con información.

En promedio, podemos decir que en estos países la composición sectorial otorga a la manufactura un $13 \%$, al comercio un $53 \%$ y a los servicios un $34 \%$. Esta información nos sugiere que aunque la actividad
CUADRO 4

América Latina (ocho países): Participación sectorial de las empresas ${ }^{a}$

(Porcentajes)

\begin{tabular}{lccc}
\hline & Manufactura & Comercio & Servicios \\
\hline Argentina & 13 & 52 & 36 \\
Colombia $^{\mathrm{b}}$ & 26 & 31 & 43 \\
Chile $^{\mathrm{c}}$ & 11 & 41 & 16 \\
Costa Rica $^{\mathrm{d}}$ & 19 & 33 & 48 \\
El Salvador $_{\text {Guatemala }}^{\mathrm{e}}$ & 11 & 62 & 27 \\
México & 16 & 47 & 37 \\
Panamá & 13 & 52 & 36 \\
\hline
\end{tabular}

Fuente: Elaboración de la FUNDES, con información recopilada por las unidades de entorno de la red FUNDES sobre la base de datos oficiales o estudios del sector.

a En algunos países las cifras pueden no sumar 100 por considerar otros sectores no incluidos aquí.

b Sólo para las PYME.

c En el rubro servicios sólo se consideran servicios personales y restaurantes. No se consideran otros sectores.

d El rubro servicios incluye transportes y comunicaciones y es sólo para las PYME.

e Sólo para las PYME.

que genera mayor valor agregado - en promedio - es la manufacturera, la actividad comercial y la de servicios son más comunes en los países de la región. Esto se debe, entre otras razones, a las condiciones del entorno, a la normativa vigente y al hecho de que las exigencias de habilidades y calificación son mayores en la rama manufacturera que en las otras dos (cabe señalar que el grueso de los servicios en América Latina son los llamados servicios personales, de poco valor agregado).

\section{III}

\section{Las condiciones del entorno de las mipyme en América Latina}

Las condiciones en que las mipyme se desenvuelven en la región no les son particularmente favorables. Esto en buena parte tiene que ver con sus competencias endógenas (bajo grado de adopción tecnológica, poca calificación de sus trabajadores y/o del propio empresario, fragilidad administrativa, baja productividad), pero también es real que ciertas condiciones del entorno (e institucionales) las afectan en mayor grado que a las grandes empresas.
$\mathrm{Al}$ respecto, cabe considerar las condiciones estructurales prevalecientes en las economías de la región cuya adaptación a las nuevas tendencias mundiales no es lo suficientemente acelerada como para rediseñar sus estructuras de cara a los nuevos retos del mundo globalizado. Entre esas estructuras se encuentran las instituciones, definidas como las reglas de juego con las que los ciudadanos (y, obviamente, las empresas) deben actuar. 


\section{El peso de las instituciones}

Muchos procesos asociados a la estabilización económica por la que pasaron los países de América Latina desde mediados del decenio de 1980 y hasta entrado el de 1990, afectaron de diferente manera y en diverso grado el desempeño de las empresas. Parte de esos procesos fue la apertura comercial, que generó un nuevo escenario para las empresas y su relación con el mercado interno y externo.

Este proceso de cambio generó expectativas en la ciudadanía latinoamericana, en la medida en que venía a reemplazar un modelo agotado. Sin embargo, la lentitud de los cambios y el escaso impacto (favorable) visible en la sociedad, entre otras cosas, hace que el modelo sea mirado con escepticismo por los ciudadanos, y que algunos logros iniciales puedan verse desdibujados por expectativas adversas (que en algunos casos pueden convertirse en profecías autocumplidas). La apatía y desconfianza que se observa en la ciudadanía ante algunas acciones públicas, e implícitamente ante instituciones y políticas, es consecuencia de lo anterior.

La confianza de los ciudadanos (y, obviamente, de los empresarios) en las instituciones sobre las que se construyen los Estados latinoamericanos es clave para entender el desempeño económico de ellos. Esto marca una diferencia con los países industrializados, donde las instituciones y el desempeño económico tienen un alto grado de independencia. En nuestra región, en cambio, las expectativas desfavorables sobre las instituciones generalmente son la antesala de resultados adversos en el desempeño económico. A veces, tales expectativas son generadas por grupos de interés que se ven afectados por las políticas en la llamada "pugna redistributiva".

Wiarda y Kline (1985) afirman que América Latina se ha convertido de manera creciente en una sociedad en conflicto, en la cual las viejas normas e instituciones han sido cuestionadas por varios nuevos grupos en los que (la sociedad) se ha dividido en torno a las futuras direcciones que seguirá el país. Señalan que un gobierno democrático puede llegar brevemente al poder, sólo para ser seguido por un nuevo régimen militar o por políticos populistas que plantean la necesidad de un programa de reformas, sólo para ser reemplazados a su vez por un gobierno oligárquicoconservador. Agregan que los conflictos en la región suelen ser profundos, las brechas entre grupos y clases en contienda son inmensas, y el resentimiento es intenso entre los que no están en el gobierno - de iz- quierda, derecha o centro- , pero que pueden llegar a él para gobernar efectivamente y esperar sobrevivir por mucho tiempo.

La sociedad latinoamericana se puede caracterizar como una sociedad dividida en grupos o sectores, cada uno de los cuales ha luchado por sus propios intereses (particular importancia tiene la pugna por recursos públicos, a la manera de los buscadores de rentas), que de alguna forma son no complementarios $\mathrm{y}$ algunas veces hasta excluyentes entre sectores. Esto se ha traducido en las disparidades entre en los diversos proyectos de desarrollo económico-social que cada uno de los diferentes grupos ha llevado a cabo cada vez que se han alternado en el poder.

De esta forma, la organización por grupos de interés (económico y político) ha sido la base para la existencia de conflictos entre capital y trabajo, entre exportadores e industriales y aun entre regiones. Aunque las pyme no son necesariamente parte de este conflicto (ya que al menos por el momento en la región no cuentan con la fuerza política suficiente para convertirse en un grupo de interés), es probable que su participación en este juego varíe en función de quienes son los ganadores y perdedores en la pugna distributiva.

Los signos visibles de tales conflictos se relacionan con los aspectos de política económica que se deciden cada vez que hay un "cambio de régimen" en los países latinoamericanos y que comprenden temas tan trascendentes como:

- El papel del Estado en la economía.

- La presencia o no de políticas de redistribución de ingresos.

- La definición de "áreas prioritarias" para el gobierno.

- La definición de la estructura impositiva.

- El tipo de política comercial.

- La política de tasas de interés (determinadas por el mercado o reguladas por el Estado en función de "objetivos estratégicos" o "sectores prioritarios").

- La política cambiaria (tipo de cambio libre, controlado, regulado).

- La política de precios.

- La política monetaria.

\footnotetext{
${ }^{4}$ Con la expresión "cambio de régimen” señalaremos, más que los cambios de administración - fruto de procesos democráticos o no-, los cambios de rumbo en la política económica como resultado de crisis políticas y/o económicas; aunque es poco probable que se dé sólo una de ellas.
} 
- La política en el mercado de trabajo (libertad de contratación y pago, participación del Estado en la definición de tales variables, esquemas mixtos).

- El papel de la inversión extranjera (entrada libre, regulada, restringida).

- El papel del Estado en la creación de leyes (de regulación de la vida social, de promoción de determinada(s) actividad(es) y otras).

Todas estas variables de política económica, permanentemente modificadas desde el gobierno, han hecho imposible que el inversionista piense en ellas como modificaciones por una sola vez de la política económica y que planee sobre esa base. El resultado de tales cambios en las variables de política mencionadas ha sido la incertidumbre $y$, por consiguiente, el retraso o directamente la retracción de las inversiones y, como consecuencia directa, la contracción de la actividad económica. La incertidumbre se refleja en el grado de confianza que le otorga la ciudadanía a las instituciones en que se fundamentan los Estados nacionales. Como vemos en el gráfico 1, las instituciones con más confianza ciudadana no son las que fundamentan a los Estados.

La desconfianza de los ciudadanos en instituciones tan importantes como la presidencia, los partidos políticos o el congreso tiene un efecto adverso en la actividad económica: i) si las condiciones prevalecientes en las economías que se encuentran en proceso de transición suponen, entre otras cosas, la presencia de viejas prácticas rezagadas del anterior modelo y estructuras burocráticas pesadas que validan las percepciones ciudadanas y que tienden a reducir la competitividad

GRAFICO

¿Cuánta confianza tiene en las siguientes instituciones? ${ }^{a}$

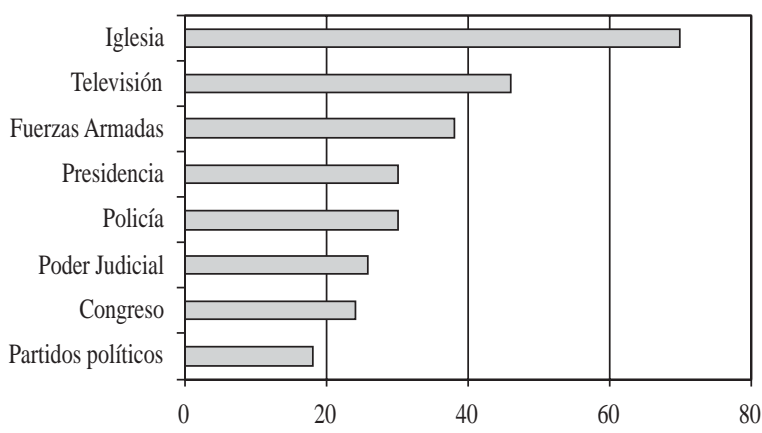

Fuente: Tomado de The Economist del 13 de diciembre de 2001. (www.economist.com), sobre información generada por Latinobarómetro.

a Porcentaje que expresó "mucha" y "alguna". inherente de las empresas; ii) si la falta de "resultados visibles" es objeto de la desconfianza de la ciudadanía, la que mete en un mismo saco las acciones públicas (positivas y negativas) y las instituciones que las llevan a cabo y las califica de inoperantes; iii) si hay apatía e incredulidad ciudadanas alrededor de las instituciones y las políticas, cuyos efectos visibles son, entre otros, la caída de la inversión y la contracción de las ventas. El impacto de estas variables sobre la formación de expectativas económicas es muy alto en la región.

La inestabilidad política y la inestabilidad económica latinoamericanas (altamente entrelazadas y ampliamente estudiadas) ${ }^{5}$ agudizan los problemas en la medida en que la existencia de escenarios inestables, al reducir la confiabilidad de los ciudadanos y la credibilidad de las instituciones, tienen efectos negativos sobre el consumo, la inversión y finalmente en el producto interno bruto (PIB). A manera de ejemplo, observemos en el cuadro 5 el desempeño del PIB en dos grupos de países (desarrollados y en desarrollo) y sus desviaciones estándares respecto al crecimiento medio.

La desviación estándar de la tasa de crecimiento del PIB muestra el grado de variabilidad de éste respecto

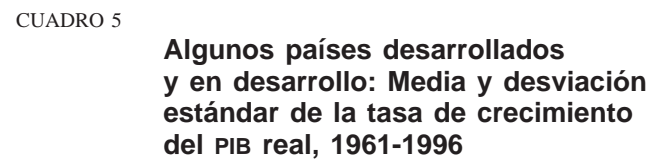

\begin{tabular}{lcc}
\hline Países & Media & $\begin{array}{c}\text { Desviación } \\
\text { estándar }\end{array}$ \\
\hline Alemania & 2.95 & 2.27 \\
Canadá & 3.78 & 2.44 \\
Estados Unidos & 3.02 & 2.13 \\
Francia & 3.32 & 2.02 \\
Italia & 3.45 & 2.56 \\
Japón & 5.53 & 3.60 \\
Reino Unido & 2.31 & 2.13 \\
Promedio países desarrollados & 3.48 & 2.45 \\
& & \\
Argentina & 2.35 & 5.37 \\
Bolivia & 3.42 & 3.15 \\
Chile & 4.09 & 5.62 \\
Costa Rica & 4.59 & 3.60 \\
México & 4.62 & 4.02 \\
Perú & 3.27 & 5.54 \\
Uruguay & 2.07 & 3.95 \\
Promedio países en desarrollo & 3.49 & 4.47 \\
& &
\end{tabular}

Fuente: Zevallos (1998).

\footnotetext{
5 Entre otros, véase Alesina y Perotti (1994); Borner, Brunetti y Weder (1992); Knack y Keefer (1995).
} 
a su valor medio. ${ }^{6}$ En los países de América Latina esta variabilidad es marcadamente más alta que en los países industrializados, aunque en promedio el crecimiento haya sido semejante. Resultado de tal inestabilidad en el crecimiento es la poca confianza de la inversión en la continuidad de las políticas.

En estas condiciones de credibilidad institucional deben llevarse a cabo las políticas públicas y las acciones de fomento empresarial. A esto se suman las exigencias de la nueva economía, que en el proceso de globalización ha desarrollado un nuevo entramado productivo e institucional que reclama de las empresas mejoras sustantivas en los procesos, flexibilidad, calidad y bajos precios, y de los países, políticas sistémicas de fomento productivo. Ante tal escenario, ¿cuáles son las condiciones exógenas que afectan el desempeño de las mipyme?

\section{Las condiciones del entorno desde la visión del empresario}

El programa Mejora de las Condiciones del Entorno Empresarial, de la FUnDEs, ha investigado en diversos países de la región cuáles son esas condiciones y cuál es la importancia relativa que los empresarios les asignan. Por nuestras propias investigaciones, contamos con un "inventario" para tres países de la región: Argentina, Colombia y Costa Rica.

Aunque las áreas de problemas de las empresas van más allá de las que presentamos a continuación, las señalamos porque, desde el punto de vista metodológico, ${ }^{7}$ abarcan la mayor cantidad de aspectos relevantes de las dificultades de las empresas de menor tamaño:

- Finanzas

- Tecnología e información

- Comercialización y comercio exterior

- Estructura regulatoria y competencia

- Organización y cooperación

- Recursos humanos

- Otros factores

Cada una de estas áreas tiene a su vez un conjunto de problemas y una jerarquización de ellos que les son propios y no necesariamente comunes a todos los países, pero que sí representan de manera suficiente la problemática general. En el cuadro 6 señalamos los

\footnotetext{
${ }^{6}$ Un valor alto de esta variable indica una gran variabilidad en la tasa de variación del PIB (inestabilidad), mientras que un valor bajo del mismo refleja poca variabilidad en el crecimiento (estabilidad).

7 Tomamos esta clasificación de FUNDES/BID (2002).
}

elementos más representativos en la relación con el entorno de tres países.

Por áreas, algunos de los ejes de la problemática son los siguientes. En el tema financiero, los empresarios se quejan del escaso acceso al sistema financiero formal como mecanismo para acceder al crédito. En el ámbito de la tecnología y la información, lo más destacable es la ausencia de tecnologías adecuadas a las empresas y la escasez de información relevante sobre mercados, oferta, demanda y otros aspectos. Asimismo, en lo que toca a la comercialización, los problemas vienen de la asimetría en la relación entre pequeñas y grandes empresas. Esto último se refleja también en la estructura regulatoria, así como en la presencia de prácticas clientelísticas y corrupción en muchas de las gestiones ante la autoridad.

La cooperación entre empresas está siendo gravemente descuidada en la medida en que existe gran asimetría en la relación entre grandes y pequeñas empresas, debido al poder de mercado de las primeras. La ausencia (o escasez) de organizaciones de representación de las pyme reduce también la posibilidad de que éstas hagan oír sus demandas. Por otra parte, la inadecuada orientación de la formación escolar, técnica y profesional conduce a sobrepoblar algunas especialidades en desmedro de otras. Además, la débil vinculación entre empresa y escuela redunda en una oferta educativa inadecuada para las necesidades productivas. Estas son algunas de las razones, según señalan los propios empresarios, por las que las empresas no logran mejorar su competitividad.

El cuadro 6 es una síntesis, por el lado de la demanda, de la situación de las empresas en su relación con el entorno. Su aporte se aclara al cruzarlo con las acciones públicas y/o privadas (el lado de la oferta) disponibles para las empresas como parte de una política sistemática de apoyo, como acciones aisladas en su favor, o como una combinación de ambas cosas.

\section{Las políticas de fomento}

¿Cuál ha sido la reacción del sector público (y/o privado) ante la problemática de las empresas de menor tamaño? No existe una única respuesta a esta pregunta. Sin embargo, un elemento común en nuestros países es el poder — al menos teórico- que se le ha asignado a la norma jurídica como respuesta a los problemas empresariales.

En muchos países de la región se tiende a pensar que la norma jurídica es la solución a muchos de los problemas que demandan acción pública, y con este 
CUADRO 6

\section{Argentina, Colombia y Costa Rica: Problemática de las} pequeñas empresas, por áreas

\begin{tabular}{|c|c|c|c|}
\hline Áreas & Argentina & Colombia & Costa Rica \\
\hline Finanzas & $\begin{array}{l}\text { Plataformas comerciales de los } \\
\text { bancos inadecuadas / poco } \\
\text { acceso al financiamiento }\end{array}$ & $\begin{array}{l}\text { Acceso al crédito / capital } \\
\text { de riesgo }\end{array}$ & $\begin{array}{l}\text { Ausencia de definición de sujetos } \\
\text { de crédito / requisitos y trámites } \\
\text { excesivos / altas tasas y plazos } \\
\text { restringidos / modalidades } \\
\text { limitadas }\end{array}$ \\
\hline
\end{tabular}

Tecnología e información

Comercialización y comercio exterior

Estructura regulatoria y competencia

Organización y cooperación

Recursos humanos

Otros
Servicios de consultoría (tecnología blanda) inadecuados

Promoción de exportaciones poco efectiva / excesivos trámites burocráticos de comercio exterior

Sobrepagos y corrupción en las tramitaciones / concentración de la oferta y/o demanda / inseguridad jurídica

Las grandes empresas no favorecen la modernización de las pyme / inadecuación de las organizaciones empresariales

Servicios de capacitación inadecuados

Bajo uso de instrumentos públicos de apoyo / costos de servicios de infraestructura
Poco acceso a la tecnología / ausencia de sistemas de información

Disposiciones de exportación / contrabando / informalidad

\section{Protección de marcas y patentes / requisitos ambientales / complejidad de la constitución de empresas / contradicción y arbitrariedad}

Falta de representación de los intereses

Cargas sociales / falta de personal calificado / otras disposiciones laborales

Cargas fiscales / invasión del espacio público / (insuficiente garantía de propiedad) / centralización
Falta de tecnologías de punta / inadecuada infraestructura tecnológica

Acceso restringido a mercados externos

Barreras de entrada al mercado interno / excesivos trámites generales de funcionamiento

\section{Encadenamientos productivos ineficaces (vinculación sectorial)} ausencia de cultura empresarial

Elevadas cargas sociales
Alto costo de los servicios públicos / poca eficacia de las políticas de promoción y fomento / insuficiente red de apoyo

Fuente: Elaboración de la FUNDES, con base en Yoguel, Moori y otros (1999), Howald (2001) y Castillo y Chávez (2001).

propósito se crean leyes, normas y reglamentos. A su vez, esta normativa generalmente tiende a generar nuevas organizaciones, en lugar de una acción pública directa. Un claro ejemplo de lo anterior es la reciente ley promulgada en Panamá el año 2000 - la Ley 8, que crea la Autoridad de la Micro, Pequeña y Mediana Empresa (ampyme) — cuyo objetivo es "Generar empleos, mejor distribución de la riqueza y reducir los niveles de pobreza ( $37 \%$ de la población del país)" (Cuevas, 2001).

Lamentablemente, no hay evidencia en América Latina de una relación positiva entre la creación de nuevas normas y la solución a los problemas que ellas buscan atacar. En realidad, muchas veces la nueva norma se incorpora a un cúmulo de otras anteriores vigentes, generando mayores costos de transacción (asociados al conocimiento y comprensión de la nueva norma) para empresas e individuos.

Otra respuesta frecuente a las demandas empresariales (o sociales), son las medidas de fomento. Sobre ellas, al igual que en los otros casos, no hay una sola posición en los países. Sin embargo, existe la tendencia a ponderar la importancia de mejorar la competitividad empresarial a través de acciones que la fortalezcan.

Adicionalmente, algunos autores ${ }^{8}$ sugieren que las políticas de fomento tienen un carácter más discursivo que real si no vienen apoyadas por los recursos económicos y humanos necesarios.

\footnotetext{
${ }^{8}$ Véase un análisis del caso de México en Dussel Peters, 2001.
} 
En todos los casos, los intentos (reales o simulados) de dar forma a una estructura que responda a las necesidades de las empresas de menor tamaño se ven sometidos a la necesidad de mantener la estabilidad macroeconómica.

Así, se presentan tres opciones que, siendo las más recurrentes, no son necesariamente las únicas: i) un marco legal específico (por ejemplo, una ley mipyme) que generalmente, pero no siempre, promueve algún tipo de organización concentradora de las acciones públicas; ii) un marco legal genérico con dimensión mipyme, es decir, con alguna consideración de las mipyme en las leyes generales (como trato preferencial en la ley fiscal, laboral y otras), y iii) medidas de fomento específicas con diversos grados de articulación entre ellas. Alrededor de estas últimas se presenta en el cuadro 7 toda la gama de propuestas de política.
En muchos países de la región parece estar generándose una corriente de apoyo a la creación de leyes de fomento empresarial. Aunque esta acción aún no tiene resultados observables en la mayoría de los países, parece ser una señal de interés que los gobiernos le están dando a las mipyme en sus políticas públicas. Iniciativas legales de este tipo hay en Argentina, Colombia, El Salvador, México, Panamá y Venezuela, entre los países examinados.

El cuadro 7 ilustra algunas de las características de lo que podríamos llamar "una política de fomento", en términos de si existe o no un marco legal específico y/o una dimensión mipyme en el marco legal general. Asimismo, muestra si hay un programa nacional de fomento productivo, quiénes son los que formulan y aplican la política, el grado de descentralización de la misma, y la participación del sector privado como respaldo importante de las medidas de apoyo.

CUADRO 7

América Latina: Aspectos básicos de la política de fomento de las mipyme

\begin{tabular}{|c|c|c|c|c|c|c|c|c|c|}
\hline & ARG & $\mathrm{BOL}^{\mathrm{a}}$ & $\mathrm{CHL}$ & $\mathrm{COL}$ & CRI & SLV & MEX & PAN & VEN $^{b}$ \\
\hline Existe un marco legal específico para las pyme & Sí & No & No & Sí & No & No & Sí & Sí & Sí \\
\hline $\begin{array}{l}\text { Existe en la normatividad genérica una dimensión pyme } \\
\text { (p. ej., artículos específicos para las pyme en la ley fiscal, } \\
\text { laboral, etc.) }\end{array}$ & Sí & No & No & No & Sí & No & No & Sí & n.c. \\
\hline Existe un programa nacional de fomento a las pyme & No & No & Sí & Sí & No & Sí & Sí & No & Sí \\
\hline $\begin{array}{l}\text { Existe en los programas generales de desarrollo una } \\
\text { dimensión pyme }\end{array}$ & No & No & Sí & Sí & Sí & No & Sí & No & Sí \\
\hline Hay organizaciones públicas especializadas en las pyme & Sí & Sí & Sí & Sí & No & Sí & Sí & Sí & Sí \\
\hline $\begin{array}{l}\text { Las políticas de fomento a las pyme tienen carácter } \\
\text { descentralizado }\end{array}$ & Sí & No & No & No & No & No & Sí & No & Sí \\
\hline $\begin{array}{l}\text { Los operadores de los programas de fomento de las } \\
\text { pyme son públicos, privados, o ambas cosas }\end{array}$ & $\begin{array}{c}\text { Los } \\
\text { dos }\end{array}$ & $\begin{array}{l}\text { Los } \\
\text { dos }\end{array}$ & $\begin{array}{l}\text { Los } \\
\text { dos }\end{array}$ & $\begin{array}{l}\text { Los } \\
\text { dos }\end{array}$ & $\begin{array}{l}\text { Los } \\
\text { dos }\end{array}$ & $\begin{array}{l}\text { Los } \\
\text { dos }\end{array}$ & $\begin{array}{l}\text { Los } \\
\text { dos }\end{array}$ & $\begin{array}{l}\text { Los } \\
\text { dos }\end{array}$ & $\begin{array}{l}\text { Los } \\
\text { dos }\end{array}$ \\
\hline $\begin{array}{l}\text { El sector privado presta servicios directos de apoyo } \\
\text { a las pyme }\end{array}$ & Sí & Sí & Sí & Sí & Sí & Sí & Sí & Sí & Sí \\
\hline $\begin{array}{l}\text { Si contestó positivamente la pregunta } 8 \text {, ¿quiénes son? } \\
\text { (p. ej., cámaras, universidades, ong, etc.) }\end{array}$ & $\mathrm{c}$ & $\mathrm{c}$ & $\mathrm{c}$ & $\mathrm{c}$ & $\mathrm{c}$ & $\mathrm{c}$ & $\mathrm{c}$ & $\mathrm{c}$ & $\mathrm{c}$ \\
\hline
\end{tabular}

Fuente: Elaboración de la FUNDES, sobre la base de una encuesta a los consultores de la unidad de entorno.

a Las políticas de apoyo se refieren a la micro y pequeña empresa.

b Se refiere a las pequeñas y medianas industrias.

c Las respuestas a la última pregunta son: Argentina: todas; Bolivia: organizaciones no gubernamentales (ONG), fundaciones; Chile: empresas y consultores privados, universidades a través de convenios con terceros, etc.; Colombia: cámaras de comercio Asociación Colombiana Popular de Industriales (ACOPI), Centro de Desarrollo Empresarial (CDE), Centro de Desarrollo Tecnológico (CDT), consultores privados, universidades, fundaciones, ONG; Costa Rica: cámaras, ONG; El Salvador: fundaciones sin fines de lucro, gremios empresariales, empresas consultoras; México: cámaras, universidades, ONG; Panamá: De servicios no financieros: FUNDES, Unión Nacional de Pequeñas y Medianas Empresas (UNPYME), Red Nacional de Organizaciones de la Micro y Pequeña Empresa (REDNOMIPEN), Universidad Latinoamericana de Ciencia y Tecnología (ULACIT), Universidad Santa María La Antigua (USMA), Universidad Latina (ULAT), Asociación Panameña de Ejecutivos (APEDE). De servicios financieros: Corporación Crediticia (CREDIFUNDES), Cooperativa de Pequeños y Medianos Empresarios (CACPYMER), Cooperativa de Ahorro y Crédito El Educador Vergüenza (COOPEVE), Cooperativa de Ahorro y Crédito San Antonio (CACSA), Multicredit Bank, Mibanco, Global Bank, etc.; Venezuela: cámaras gremiales (Conindustria, Fedeindustria), ONG como el programa Bolívar y el Centro al Servicio de la Acción Popular (CESAP). 
Así como existe cierta corriente en pro del fomento de la competitividad empresarial (que en América Latina se refleja en el creciente interés por establecer una normativa específica para las pyme), se ha observado también un intento de favorecer determinadas orientaciones o componentes en la estructura de las medidas de apoyo y/o programas de fomento empresarial. Así, por ejemplo, estas medidas y programas:

- Buscan subsanar fallas de mercado.

- Se basan en el principio de subsidiariedad.

- Están orientados a la demanda.

- Buscan la participación del sector privado (a través del financiamiento, la ejecución, etc.).

- Se fundamentan en políticas horizontales (uniformes).

- Los programas de fomento cubren diferentes necesidades.

- La variable típica de evaluación de los programas (cuando existe) es el número de empresas atendidas.

Sin embargo, vale la pena señalar que en varios países de la región (sobre todo los que exhiben más avance institucional y mayor desarrollo de sus políticas de fomento) algunas de estas características empiezan a ser reemplazadas por otras con una mayor orientación a sectores o nichos de mercado.

En ese sentido, el criterio de análisis basado en la orientación al mercado del modelo prevaleciente comienza a ser complementado con criterios como el de competitividad sistémica (Esser, Hillebrand y otros 1994), el de competitividad microeconómica (Porter, 2001) y otros. Con ellos se buscan soluciones híbridas respecto a la participación del Estado en la economía: del Estado "facilitador" por las líneas del Estado mínimo (Nozick, 1991), que se limita a proteger a los ciudadanos de la violencia y el robo y a favorecer el cumplimiento de los contratos, se pasa al Estado "promotor", que busca eliminar o disminuir los obstáculos del entorno para mejorar la competitividad de las empresas, maximizando de esta forma el impacto de las acciones públicas y privadas de apoyo.

De las opciones de política que adoptan los países y de las características de las políticas que aplican derivan acciones concretas en cada una de las áreas enumeradas en el cuadro 6. El cuadro 7, por su lado, ofreció una visión panorámica de la estructura de apoyo ("la política de fomento") de los países para las pyme. A continuación, el cuadro 8 muestra (para las mismas áreas señaladas en el cuadro 6) la oferta de acciones de apoyo a las mipyme y los programas respectivos, sobre la base de los resultados de una breve encuesta que efectuamos entre los consultores de la red FUNDES en nueve países. Cabe señalar que en este artículo no se evalúa la eficiencia de los programas ni su consistencia interna; sólo se busca informar sobre los instrumentos de apoyo disponibles en los países de la región considerados.

La descripción que hacemos aquí no es exhaustiva, sino simplemente el resultado de una indagación sobre las acciones de promoción más frecuentes en los países de América Latina, y en ese ámbito, sobre un conjunto de áreas también reconocidas como las más comunes. El propósito es identificar los "espacios

CUADRO 8

América Latina y el Caribe: Líneas más comunes de apoyo a las mipyme

Existe $=\mathrm{X} \quad$ No existe $=0 \quad$ No contestó $=\mathrm{NC}$

Argentina Chile Colombia Costa El Guatemala México Panamá Venezuela Rica Salvador

\section{Finanzas}

Sistemas de garantía de préstamos

Préstamos para mipyme

Fondos de capital de riesgo

Leasing

Factoring

Bonificación de primas de seguros de crédito

Bonificación (subsidio) a la tasa de interés

Microcréditos (a microempresas/de pequeño monto)

Factura de crédito (duplicata); financiarse con proveedores

Servicios de asistencia financiera

Otros instrumentos financieros

Préstamos para mipyme, dirigidas por mujeres

Ayuda financiera para nuevos emprendimientos (capital semilla)

Fondos regionales de inversión

$\begin{array}{cccc}X & X & X & 0 \\ X & X & X & X \\ X & X & 0 & 0 \\ X & X & X & X \\ X & 0 & X & X \\ 0 & X & 0 & 0 \\ X & 0 & 0 & 0 \\ X & X & X & X \\ X & 0 & 0 & X \\ X & X & X & X \\ X & X & X & 0 \\ X & 0 & X & X \\ 0 & X & X & 0 \\ X & 0 & \text { NC } & 0\end{array}$

\begin{tabular}{ccccc}
0 & 0 & $\mathrm{X}$ & 0 & $\mathrm{X}$ \\
$\mathrm{X}$ & $\mathrm{X}$ & $\mathrm{X}$ & $\mathrm{X}$ & $\mathrm{X}$ \\
0 & 0 & $\mathrm{X}$ & 0 & 0 \\
0 & $\mathrm{X}$ & $\mathrm{X}$ & $\mathrm{X}$ & 0 \\
$\mathrm{X}$ & 0 & $\mathrm{X}$ & $\mathrm{X}$ & 0 \\
0 & 0 & $\mathrm{X}$ & $\mathrm{NC}$ & 0 \\
0 & 0 & $\mathrm{X}$ & 0 & $\mathrm{X}$ \\
$\mathrm{X}$ & $\mathrm{X}$ & $\mathrm{X}$ & $\mathrm{X}$ & $\mathrm{X}$ \\
$\mathrm{X}$ & 0 & $\mathrm{X}$ & $\mathrm{X}$ & $\mathrm{NC}$ \\
$\mathrm{X}$ & $\mathrm{X}$ & $\mathrm{X}$ & $\mathrm{X}$ & $\mathrm{NC}$ \\
0 & 0 & $\mathrm{X}$ & $\mathrm{NC}$ & $\mathrm{X}$ \\
0 & $\mathrm{X}$ & $\mathrm{X}$ & $\mathrm{X}$ & $\mathrm{X}$ \\
0 & 0 & $\mathrm{X}$ & 0 & 0 \\
0 & 0 & $\mathrm{X}$ & 0 & 0 \\
\hline
\end{tabular}

(Continúa en página siguiente) 
Argentina Chile Colombia Costa El Guatemala México Panamá Venezuela Rica Salvador

Tecnología e información

Apoyo financiero

Crédito fiscal para I + D

Consejería tecnológica

Incubadoras de empresas

Parques tecnológicos

One stop shop

Otros programas de tecnología o información

Programas de restructuración y apoyo a la gestión de mipyme

- Consejeros empresariales

- Fomento de la competitividad

- Programas de calidad

- Otros programas especiales

Fondos de asistencia técnica

Rica Salvador

\section{Comercialización y Comercio Exterior}

Programas especiales

- Fondos

- Programas para nuevos exportadores

- Otros programas

Información de mercados

Apoyo a promoción comercial

Asistencia a ferias

Folletería

Servicios de promoción de exportaciones

$\begin{array}{ccccccccc}\mathrm{X} & \mathrm{X} & \mathrm{X} & \mathrm{X} & 0 & 0 & \mathrm{X} & \mathrm{X} & \mathrm{X} \\ \mathrm{NC} & \mathrm{X} & \mathrm{X} & 0 & \mathrm{X} & 0 & \mathrm{X} & \mathrm{X} & \mathrm{X} \\ 0 & 0 & \mathrm{X} & 0 & \mathrm{X} & 0 & \mathrm{X} & \mathrm{X} & \mathrm{X} \\ \mathrm{X} & 0 & \mathrm{X} & \mathrm{X} & \mathrm{X} & 0 & \mathrm{X} & \mathrm{X} & \mathrm{X} \\ \mathrm{X} & 0 & \mathrm{X} & \mathrm{X} & 0 & 0 & \mathrm{X} & \mathrm{X} & \mathrm{X} \\ 0 & 0 & \mathrm{NC} & \mathrm{NC} & \mathrm{X} & 0 & \mathrm{X} & 0 & \mathrm{NC} \\ \mathrm{X} & \mathrm{X} & \mathrm{NC} & \mathrm{NC} & \mathrm{X} & 0 & \mathrm{X} & \mathrm{NC} & \mathrm{X} \\ \mathrm{X} & 0 & \mathrm{NC} & \mathrm{NC} & \mathrm{X} & \mathrm{NC} & \mathrm{X} & \mathrm{X} & \mathrm{X} \\ \mathrm{X} & 0 & \mathrm{X} & 0 & 0 & 0 & \mathrm{X} & \mathrm{X} & 0 \\ \mathrm{X} & 0 & \mathrm{X} & 0 & \mathrm{X} & \mathrm{X} & \mathrm{X} & \mathrm{X} & \mathrm{X} \\ \mathrm{X} & 0 & \mathrm{X} & \mathrm{X} & 0 & 0 & \mathrm{X} & \mathrm{X} & \mathrm{X} \\ \mathrm{X} & 0 & \mathrm{X} & 0 & 0 & 0 & \mathrm{X} & \mathrm{X} & \mathrm{NC} \\ \mathrm{X} & \mathrm{X} & \mathrm{NC} & 0 & \mathrm{X} & 0 & \mathrm{X} & \mathrm{X} & \mathrm{X}\end{array}$

\section{Estructura regulatoria y competencia}

Evaluación de impacto empresarial

Revisión de la estructura tributaria

Simplificación de trámites para:

- registro de empresas

- pago de impuestos

- exportar (reintegro)

Flexibilización del mercado laboral

Modernización de la gestión pública

\section{Organización y cooperación}

Organizaciones que impulsan los valores

emprendedores, a través de foros, documentos, etc.

Redes empresariales territoriales (clusters)

Fortalecimiento municipal

Mejora de gestión en recursos humanos

Promoción a la localización territorial

Centros de servicios no financieros de ámbito local

Agencias de desarrollo regional (para acercar

instrumentos nacionales al ámbito local)

\section{Recursos humanos}

Crédito fiscal para capacitación

Capacitación laboral:

- mujeres / jóvenes

- empresarios

- trabajadores

Programa nacional de capacitación

Servicios privados de capacitación

Servicios públicos de capacitación

\section{Otras acciones}

Mejora en los servicios públicos (infraestructura)

Programas (especiales) suponen cofinanciamiento o determinado grado de subsidio a la empresa

Otras acciones (especificar)

Fuente: Elaboración de la FUNDES sobre la base de una encuesta a los consultores de las unidades de entorno de la red FUNDES en nueve países. 
vacíos" entre las medidas de fomento y la demanda de las empresas y, a la vez, generar un debate sobre el uso de los recursos económicos invertidos en la promoción con miras a optimizarlo.

\section{Algunos espacios vacíos}

Pese a la amplitud de la lista de aspectos básicos de política de fomento que aparece en el cuadro 7, las demandas de los empresarios suelen ser muchas, no tanto por la falta de acciones sino por su ineficacia. De ahí la importancia de indagar más a fondo en la operatoria de los programas mismos. Como parte de las investigaciones del Programa Mejoramiento de las Condiciones del Entorno Empresarial a nivel internacional, se han recogido algunos de los problemas que los empresarios señalan:

- Existen severos problemas de información que inciden en que las decisiones (públicas y privadas) se tomen sobre la base de información deficiente.

- Las propias percepciones (más o menos informadas) de los responsables de las políticas de fomento se convierten en la base de las acciones, muchas veces sin que se consulte a sus potenciales beneficiarios: los empresarios.

- Hay carencias de recursos económicos y humanos para aplicar una decidida política descentralizadora.

- Es poca la difusión de los programas a nivel nacional (federal), departamental (estadual) y local (problemas de información).

- Los programas se concentran fuertemente en la capital o en áreas relativamente más desarrolla- das (grandes ciudades). Si bien esto reconoce la concentración empresarial, deja desvalidas a las empresas de otras zonas, manteniendo la concentración de la oferta.

- Hay poca coordinación entre instituciones de fomento del sector público (ministerios y otras dependencias), entre el sector público y el privado (entre gobierno y cámaras y gremios), así como entre el gobierno nacional y los gobiernos estaduales (departamentales).

- Hay poca integración entre empresa y escuela (lo que se refleja en el creciente desempleo o subempleo profesional debido a la falta de diálogo sobre inversión en programas útiles para la actividad productiva).

- En varios programas de fomento, los requisitos de acceso tienden a sacar del mercado a un número significativo de empresas. Si el objetivo es la selectividad la variable es la correcta, pero no puede serlo en contextos donde se plantea la horizontalidad como principio de la acción pública.

Quizás el elemento más representativo de la problemática descrita, vista desde el lado de la oferta, es la deficiente coordinación entre dependencias del gobierno nacional, y entre ellas y los gobiernos locales.

La insuficiente coordinación, a su vez, resulta del aislamiento en el que se generan las acciones de apoyo, la baja participación de los involucrados en la generación de soluciones, el poco contacto de los agentes públicos con la realidad de las empresas, y la escasa colaboración entre organizaciones del Estado que compiten por espacio dentro del sistema de gobierno.

\section{IV}

\section{Oportunidades de mejoramiento}

Una acción integral de fomento empresarial supone abarcar desde la definición de la orientación económica de mediano y largo plazo hasta el fomento de valores empresariales y de colaboración. Obviamente ésta es una labor de largo plazo. Sin embargo, en las áreas señaladas es posible establecer ciertos puentes que pueden reducir la brecha entre las demandas de los empresarios y la oferta de servicios.

\section{Finanzas}

Un problema recurrente para las empresas es el del acceso al capital. Este problema deriva de fallas en el mercado de capitales, como el escaso financiamiento de capital de riesgo, los excesivos trámites, las altas tasas y los plazos restringidos.

Sin embargo, cabe señalar que entre las líneas de apoyo examinadas existe el rubro de préstamos para 
las mipyme, así como el de microcréditos. Lo paradójico es que en todos los países se hace presente que existen líneas de crédito para estos estratos empresariales. $\mathrm{Al}$ respecto, nuestro trabajo es averiguar por qué la oferta no está llegando a la demanda, al menos en los montos (plazos y/o condiciones) suficientes, y también cuál es el grado de penetración de la oferta financiera en el mercado y qué mecanismos pueden crearse para mejorar el acceso y las condiciones de financiamiento. Esta es un área de especial interés en países donde las reformas institucionales están comenzando, o donde no hay experiencia con mecanismos modernos de financiamiento.

\section{Tecnología e información}

En esta área, los problemas principales son la ausencia de tecnología apropiada a costos accesibles, y por otro lado, el poco acceso a la tecnología existente, tanto en la actualización de equipos o maquinaria, diseño de productos y aspectos similares, como en la gestión y capacitación gerencial. Además, la falta de sistemas de información eficaces (sobre proveedores, compradores y otros) también restringe el desarrollo competitivo de las firmas.

En el tema tecnológico, a diferencia del financiero, se observa mayor heterogeneidad en las líneas de apoyo, lo que muestra claramente la falta de rumbo de los programas en esta área. En varios de los países de la región considerados no se cuenta con programas o no hay conocimiento de su existencia. Aunque su menor desarrollo relativo es lo que suele poner límites a sus posibilidades tecnológicas, no deja de constituir una oportunidad para que desarrollen proyectos tecnológicos de impacto. Un elemento importante en ese sentido es que en casi todos estos países existen apoyos financieros para desarrollo tecnológico.

En el tema de la información, la mayoría de los países latinoamericanos examinados carece de sistemas de suministro de toda la información pertinente en un solo lugar (one-stop-shop). Sin embargo, algunos de ellos han empezado a establecer ventanillas únicas (para trámites), con el apoyo de organizaciones intermedias nacionales o internacionales. Esta sería una oportunidad de aplicar en ellos experiencias exitosas en otros países de la región.

\section{Comercialización y comercio exterior}

Este tema está cobrando creciente importancia para las mipyme, ya que existe un segmento pequeño pero cre- ciente de ellas que empieza a incursionar con éxito en el mercado externo. Los problemas que las aquejan son claramente el acceso a la información y los servicios, y algunas disposiciones y/o trámites que obstaculizan el comercio, entre otros. En cuanto a los mercados, la presencia del sector informal como competencia desleal para las empresas formales también constituye una limitación (y, en algunos casos, hasta un incentivo para "informalizar" algunas actividades).

Obviamente, las posibilidades de acceso a mercados externos que tienen las mipyme dependen de sus condiciones endógenas (como la calidad de su producto, el precio y la oportunidad de acceder a esos mercados). Sin embargo, la calidad de la infraestructura de transportes y comunicaciones, así como la presencia de una infraestructura de apoyo logístico y de información que facilite la tarea del exportador, son ventajas competitivas en las que el sector público y el privado pueden colaborar y que permitirán a las mipyme exportadoras entrar a nuevos mercados. Es posible generar mecanismos de asistencia e información a las mipyme exportadoras a partir de one-stop-shops que complementen la labor de ventanilla única con servicios de información y asistencia.

Por otra parte, resolver el problema de la informalidad escapa a las posibilidades institucionales, por lo que debe ser encarado mediante un esfuerzo conjunto de la sociedad entera. Sin embargo, la generación de mecanismos para "formalizar" empresas bajo esquemas simplificados, sin ser una solución, suele mejorar las condiciones de acceso de las empresas a la formalización, reduciendo el incentivo para incorporarse o permanecer en el sector informal.

\section{Estructura regulatoria y competencia}

Los países de la región, en su mayoría, han pasado ya por un proceso de ajuste y reforma estructural, y se encuentran (más o menos adelantados) en un segundo proceso, denominado de reforma institucional. En este punto, la burocracia y sus aspectos más negativos (arbitrariedad, corrupción, discrecionalidad) son los obstáculos que con más más frecuencia mencionan los empresarios. También la falta de protección de marcas y patentes (piratería), los requisitos ambientales y la propia inseguridad jurídica se convierten en un problema particularmente delicado para la actividad económica.

Sin embargo, a estas alturas del proceso la respuesta de política tiende a ser más lenta, porque 
generalmente los hábitos adquiridos por las instituciones $^{9}$ (y sus normas informales de funcionamiento) son más difíciles de cambiar. En ese sentido, la mayor parte de los países está revisando sus procedimientos, modernizando su administración e incluso flexibilizando legislación que tiene impacto en la competitividad (la laboral, por ejemplo). En esta tarea es preciso revisar las "mejores prácticas factibles" 10 para adaptarlas a nuestras realidades.

\section{Organización y cooperación}

En este tema hay tres percepciones de los empresarios que debemos tomar en cuenta: i) la falta de cooperación entre las empresas, aspecto particularmente complejo porque involucra el factor humano y su vocación a cooperar o a organizarse en grupos; ii) la existencia de una relación marcadamente asimétrica entre las mipyme y las grandes empresas, que favorece a estas últimas, y iii) la ausencia de cultura empresarial en nuestras sociedades.

Dos de estas percepciones tienen que ver con el tema de la educación como formación para la vida. Este tema rebasa el papel de las organizaciones intermedias, puesto que forma parte de la política pública en el ámbito educativo, aunque también se relaciona con la educación en el hogar y el fomento de hábitos de colaboración, entre otros aspectos.

Por otro lado, uno de los problemas más importantes en cuanto a asociatividad es la falta de representación institucional: en la mayor parte de los países de la región examinados, los gremios empresariales agrupan a menos del $1 \%$ de todas las empresas. Esto es mucho más marcado aún entre las mipyme, cuya representación generalmente se encuentra subsumida en organizaciones gremiales dominadas por grandes empresas, que tienen otros intereses. Esta situación contrasta, por ejemplo, con la de Taiwán, donde la representación de las pyme tiene un peso político muy significativo. Un tema de mediano plazo podría ser el de generar mecanismos de representación de las mipyme.

La relación asimétrica entre las grandes empresas y las mipyme - la ausencia de encadenamientos productivos, entre otros- es un importante obstáculo al desarrollo de estas últimas. La respuesta pública (y privada) a este problema es muy fragmentaria y a veces inexistente. Algunos países han buscado salidas legales a partir de leyes de fomento de la competencia, pero el alcance de ellas ha sido muy limitado.

\section{Recursos humanos}

En este tema se mezclan dos importantes aspectos: i) la visión del empresario sobre las cargas sociales que representa el trabajador para la empresa, y ii) la eficacia de los instrumentos de capacitación laboral. Al tema de la calificación laboral debemos incorporar el de la calificación empresarial.

Las cargas sociales que existen en muchos países tienen un peso relativo muy variable. El proceso de flexibilización laboral se ha dado en América Latina ya sea a través del marco legal (cambios en las leyes), ya sea de facto, mediante mecanismos informales de contratación. El Estado debe buscar en este caso un equilibrio entre el fomento de la competitividad empresarial y la necesaria protección del trabajador.

Sobre el segundo punto, en casi todos los países de la red FUNDES hay programas de capacitación, públicos y/o privados. Sin embargo, cabe preguntarse cuán amplia es su difusión, cuál es su utilidad y cuál es su relación calidad-precio. Tales interrogantes tienen particular relevancia para las organizaciones que ofrecen estos servicios. Una línea de acción institucional sería la de hacer un inventario de los instrumentos de calificación (laboral y empresarial) existentes en los países, evaluar la eficacia de esos instrumentos en comparación con las herramientas de la organización oferente, y ofrecer a los gobiernos servicios que cuenten con una evaluación de eficacia (certificada, por ejemplo, por un organismo externo).

\footnotetext{
${ }^{9}$ El caso de México y el Programa Solidaridad es ilustrativo. Ante la imposibilidad de modernizar las estructuras burocráticas para mejorar la eficacia de este programa, el Presidente Salinas de Gortari creó una "burocracia paralela" encargada de desarrollarlo. Evidentemente, el resultado fue mejor de lo que hubiera sido con la burocracia institucional.
}

\footnotetext{
10 Concepto acuñado por Albert Berry para señalar la posibilidad de "adaptar" soluciones generadas en países donde el grado de desarrollo económico e institucional genera condiciones iniciales muy superiores a las de los países menos desarrollados.
} 


\section{V}

\section{Conclusiones}

La situación de las mipyme en la región revela vacíos importantes en áreas que van desde la propia información estadística disponible hasta las políticas públicas de los países y las acciones de fomento específicas. Este escenario plantea grandes desafíos, pero también interesantes posibilidades.

El presente artículo aporta información sobre el universo de empresas, su distribución espacial y sectorial, y también sobre la demanda de las mipyme y la oferta de "productos" para las empresas de menor tamaño, que es muy significativa.

La mayor parte de los países de la región clasifican a las mipyme en función del empleo. En general, las pyme oscilan entre el $3 \%$ y el $20 \%$ del número de unidades económicas, dependiendo de la cantidad de microempresas existente en cada país. Pero si introducimos en el grupo de las pyme a las microempresas "de acumulación" o "con opción de desarrollo", el porcentaje se incrementa significativamente. Esto nos lleva a pensar en la posibilidad de adoptar un concepto más amplio de pyme (como el de "empresa media" aplicado en México). Esta definición amplia tendería a incorporar a las políticas de fomento productivo a unidades económicas que en este momento sólo pueden acceder a mecanismos de apoyo que perpetúan una situación de supervivencia.

De otro lado, las condiciones del entorno de negocios en la región reflejan situaciones que van más allá de los aspectos más puntuales de apoyo, como la propia estructura económica y política de los países, la variabilidad de sus políticas económicas y la incertidumbre que esa variabilidad genera.

Si quisiéramos tipificar el entorno público de las empresas de menor tamaño en la región, habría que señalar tres componentes principales: i) la propia inestabilidad de nuestras economías, que no fomenta la inversión y que distorsiona los precios relativos y, por ende, la estructura de incentivos, deteriorando la confianza en el desempeño económico y - eventualmente- en la cooperación entre empresas; ii) la insuficiente comprensión por parte de los gobiernos de la problemática de las mipyme, y iii) la poca eficacia de los mecanismos institucionales del Estado (estructura) para resolver los dilemas de política pública en el ámbito empresarial.
Estos tres componentes ejercen una influencia significativa en el funcionamiento de las empresas. El primero incide en la actividad económica en su conjunto, incrementando la inestabilidad de la economía $\mathrm{y}$, por lo tanto, la incertidumbre; el impacto sobre las unidades económicas más pequeñas es mayor porque tienen menos mecanismos de defensa ante las fluctuaciones económicas que las grandes empresas. El segundo reduce las posibilidades de las empresas de contar con mecanismos eficaces para atacar sus problemas, ya que en la política de fomento hay vacíos o excesiva concentración de acciones en un área que terminan siendo redundantes, elementos que ahondan las desventajas en la competitividad de las mipyme. El tercer componente tiene un impacto que es más bien de carácter operativo, ya que tiene que ver con problemas en la relación cotidiana de trabajo entre las empresas y el Estado (burocratismo, discrecionalidad, grado de cumplimiento de las normas).

En lo que respecta a la inestabilidad económica, son los gobiernos - en colaboración con la iniciativa privada, las organizaciones intermedias y otros interlocutores sociales válidos- los que deben definir un rumbo de mediano y largo plazo, generar acuerdos mínimos y tomar medidas consistentes con esos propósitos. La acción de las organizaciones intermedias es periférica y se limita a apoyar las medidas que tiendan a generar estabilidad (económica y política) en las economías nacionales.

En los otros componentes el papel de las organizaciones intermedias se hace más significativo. Respecto al segundo, la mayor parte de los gobiernos nacionales cuenta con varios instrumentos en cada una de las áreas identificadas como problemáticas por los empresarios. Sin embargo, las medidas que toman no vienen precedidas de un diagnóstico de la demanda, sino que se basan más bien en las percepciones (más o menos informadas) de los políticos y los operadores públicos. Desde hace varios años, la idea de contratar externamente servicios que antes proveía el Estado ha venido adquiriendo fuerza. En tales tareas, los Estados deben aprovechar el bagaje institucional de las organizaciones intermedias.

En cuanto al tercer componente, la eficacia para llevar a cabo las soluciones tiene que ver con el diseño de los programas, que a su vez se vincula estrechamente 
con el diagnóstico de los problemas. Una adecuada comprensión de estos problemas es la base para encontrar soluciones válidas, por lo que es útil acercarse a quienes los conocen mejor, es decir, a los empresarios. Su participación en la generación de soluciones es una garantía de éxito.

La FUNDES ha estado trabajando para identificar los "obstáculos del entorno"11 que afectan el desempeño de las empresas de menor tamaño. Esta labor ha servido de base al diseño y la ejecución de acciones específicas para resolver problemas empresariales en varios países de la región. Iniciativas como las de ventanilla unificada (Argentina), simplificación de trámites (Costa Rica) y fomento de un sistema impositivo para las mipyme (Colombia) resultaron de esfuerzos por diagnosticar los problemas del entorno empresarial.
Esfuerzos pequeños, pero consistentes, constituyen la base para desarrollar acciones más integradas. América Latina ha venido avanzando en esa dirección; sin embargo, la insuficiencia de la información sigue siendo un obstáculo crucial para elaborar estrategias mejor orientadas. Efectuar buenos diagnósticos es otra condición necesaria para desarrollar una política coherente con las necesidades de la planta productiva. Los planes y programas con objetivos bien definidos permiten generar indicadores de logro, importantes cuando los recursos son escasos. Finalmente, el trabajo conjunto de un sector privado cohesionado y colaborativo y de un sector público profesional y comprometido es un elemento complementario importante para llevar a cabo una estrategia de desarrollo empresarial.

\section{Bibliografía}

Alburquerque, F. (1997): La importancia de la producción local y de la pequeña empresa para el desarrollo de América Latina, Revista de la CEPAL, № 63, LC/G.198P, Santiago de Chile, diciembre.

Alesina, A. y R. Perotti (1994): The political economy of growth: a critical survey of the recent literature, The World Bank Economic Review, vol. 8, $\mathrm{N}^{\circ} 3$.

Berry, A. (1998): Las tareas de la pequeña y mediana empresa en América Latina, Revista de la CEPAL, número extraordinario, LC/G.2037-P CEPAL, Santiago de Chile, octubre.

Borner, S., A. Brunetti y B. Weder (1992): Institutional obstacles to Latin American growth. International Center for Economic Growth, Ocassional paper, N 24, San Francisco, ICs Press, 1992.

Castillo, G. y L. Chávez (2001): Pymes, una oportunidad de desarrollo para Costa Rica, San José de Costa Rica, Publicaciones FUNDES.

CONAMYPE (Comisión Nacional de la Pequeña y Mediana Empresa) (1995): Encuesta de la microempresa salvadoreña, San Salvador, julio.

(2002): Encuesta nacional económica 2002, San Salvador.

Cuevas, A. (2001): Aspectos relevantes de la ley 8 y 33 del año 2000, ponencia presentada en el tercer Taller Internacional de la Red Entorno, Panamá, Fundación para el Desarrollo Económico y Social (FUNDES), agosto.

DANE (Departamento Administrativo Nacional de Estadística) (1991): Censo económico y multisectorial, Bogotá, D.C.

Dussel Peters, E. (2001): Claroscuros, integración exitosa de las pequeñas y medianas empresas en México, México, D.F., Cámara Nacional de la Industria de Transformación/ Comisión Económica para América Latina y el Caribe (CANACINTRA/CEPAL), Editorial Jus.

Esser, Klaus, Wolfgang Hillebrand y otros (1994): Competitividad sistémica, competitividad internacional de las empresas y políticas requeridas, Berlín, Instituto Alemán de Desarrollo.

${ }^{11}$ Definidos como todos los principales problemas que perjudican a las pyme en el inicio, desarrollo o diversificación de sus actividades económicas (FUNDES, 2000, p. 6).
FUNDES (Fundación para el Desarrollo Económico y Social) (2000): Guía metodológica del Programa "Mejora de las condiciones de entorno empresarial", http://home.fundes.org/ documentos.htm\#27.

FUNDES/BID (Fundación para la Economía y el Desarrollo/Banco Interamericano de Desarrollo) (2002): Guía para el análisis, valoración y diseño de políticas de desarrollo de la pequeña empresa, http://www.iadb.org/sds/SME/publication/gen 168 2279_s.htm.

Howald, F. (2001): Obstáculos al desarrollo de la Pyme causados por el Estado, el caso del sistema tributario en Colombia, Bogotá, D.F., Publicaciones FUNDES.

INDEC ( Instituto Nacional de Estadística y Censos) (1994): Censo nacional económico, 1994, Buenos Aires.

Knack, S. y P. Keefer (1995): Institutions and economic performance: cross country test using alternative institutional measures, Economics and Politics, vol. 7, $\mathrm{N}^{\circ} 3$, noviembre.

Nozick, R. (1991): Anarquía, Estado y utopía, México, D.F., Fondo de Cultura Económica.

OCDE (Organización de Cooperación y Desarrollo Económicos) (1997): Globalisation and Small and Medium Enterprises (SMEs), vol. 1, París.

Páez, Tomás (2001): Observatorio PYME: Estudio de la pequeña y mediana empresa en Venezuela, Caracas.

Porter, M. (2001): Enhancing the microeconomic foundations of prosperity: the current competitiveness index, The Global Competitiveness Report, 2001-2002, Nueva York, Oxford University Press.

The Economist (2001): The Latinobarometro poll, an alarm call for Latin America's democrats, 13 de diciembre.

Wiarda, H. y H. Kline, eds. (1985): Latin American Politics and Development, Oxford, Westview Press.

Yoguel, Gabriel, Virginia Moori y otros (1999): Los problemas del entorno de negocios. El desarrollo competitivo de las pymes argentinas, Buenos Aires, Publicaciones FUNDES.

Zevallos, E. (1998): Tendencia y variabilidad en el desempeño económico; análisis empírico comparativo de países desarrollados versus subdesarrollados, tesis de Maestría en Economía, México, D.F., Instituto Tecnológico Autónomo de México (ITAM).

(2000): Empresa media: una nueva clasificación, Comercio exterior, México, D.F., vol. $50, \mathrm{~N}^{\circ} 3$, marzo. 